\title{
Delayed Postischemic Hypothermia Improves Long-Term Behavioral Outcome after Cerebral Hypoxia-Ischemia in Neonatal Rats
}

\author{
BENDICHT PETER WAGNER, JOHANN NEDELCU,† AND ERNST MARTIN \\ Pediatric Intensive Care, Department of Pediatrics, University of Berne, Inselspital, Berne, Switzerland \\ [B.P.W.]; Neuroradiology and Magnetic Resonance Research, Department of Diagnostic Imaging, \\ University Children's Hospital Zurich, Zürich, Switzerland [J.N., E.M.]
}

\begin{abstract}
ABSTRA
Hypothermia may be an ideal neuroprotective intervention in
hypoxic-ischemic encephalopathy after perinatal asphyxia. The
present study describes the long-term effects of prolonged resus-
citative whole-body hypothermia initiated 2 h after hypoxic-
ischemic injury on brain morphology and neuropsychological
behavior in 7 -d-old rats. After right common carotid artery
ligation and exposure to hypoxia of $8 \% \mathrm{O}_{2}$ for 105 min, 10
animals were kept normothermic at $37^{\circ} \mathrm{C}$ and 10 animals were
cooled to $30^{\circ} \mathrm{C}$ rectal temperature for $26 \mathrm{~h}$, starting $2 \mathrm{~h}$ after the
hypoxic-ischemic insult. All hypoxic-ischemic animals were ga-
vage fed to guarantee long-term survival. Neuroprotection was
evaluated by magnetic resonance imaging and behavioral testing.
Hypothermia significantly reduced the final size of cerebral
infarction by $23 \%$ at 6 wk after the insult. The most extended
tissue rescue was found in the hippocampus $(21 \%, p=0.031)$,
followed by the striatum (13\%, $p=0.143)$ and the cortex $(11 \%$,
$p=0.160)$. Cooling salvaged spatial memory deficits verified at
5 wk of recovery with Morris Water Maze test; whereas circling
abnormalities after apomorphine injection and sensory motor
dysfunctions on rotating treadmill improved, yet did not reach
statistical significance. When compared with controls, hypoxic-
\end{abstract}
ischemic animals performed worse in all behavioral tests. Hypothermia did not influence functional outcome in controls. Significant correlations between behavioral performance and corresponding regional brain volumes were found. We conclude that $26 \mathrm{~h}$ of mild to moderate resuscitative hypothermia leads not only to brain tissue rescue, but most important to long-lasting behavioral improvement throughout brain maturation despite severity of injury and delayed onset of cooling. (Pediatr Res 51: 354-360, 2002)

$\quad$ Abbreviations
MRI, magnetic resonance imaging
HI, hypoxia-ischemia
T,WI, T2-weighted imaging
DWI, diffusion weighted imaging
MWM, Morris Water Maze
IH, ischemia with hypothermia
IN, ischemia with normothermia
CH, control with hypothermia
CN, control with normothermia

Perinatal asphyxia represents, according to the definition of the American Academy of Pediatrics and American College of Obstetricians (1), a profound, hypoxic-ischemic insult in the human fetus and newborn with a high rate of permanent neuropsychological damage and mortality. A severe acute insult may predominantly affect the thalami, the basal ganglia, the hippocampus, and the brain stem with relative preservation of the cerebral cortex and the subcortical white matter (2). After birth, the clinical signs of perinatal asphyxia include neurologic abnormalities such as coma, seizures, or hypotonia, combined with cardiopulmonary compromise. The newly born infant often requires resuscitation and rapid transfer to the

Received December 24, 2000; accepted September 26, 2001.

Correspondence and reprint requests: Bendicht Wagner, Pediatric Intensive Care, Inselspital, 3010 Bern, Switzerland; e-mail: wagner@insel.ch

†Deceased. tertiary center for injury severity evaluation and neurologic intensive care. Such support could include specific interventions for hypoxic-ischemic encephalopathy 1 or $2 \mathrm{~h}$ into the reperfusion phase from cerebral HI. Despite the fact that perinatal asphyxia closely corresponds to experimental models of cerebral HI, where successful neuroprotective interventions were introduced, presently no agent has been proven useful to ameliorate the chronic handicapping conditions of perinatal asphyxia in the clinical setting (3).

In the present clinical situation, neuroprotection can at best be initiated hours after perinatal asphyxia. Such a postischemic or resuscitative neuroprotective measure is hypothermia, which has been explored since the 1950s. The first clinical trials were reported after perinatal asphyxia $(4,5)$, and cardiac arrest (6). Eventually, postischemic hypothermia was abandoned because the trials lacked control conditions and because it was shown 
that constant warm ambient temperature significantly reduced mortality in premature newborns (7). In the 1980s, postischemic hypothermia was revived because it ameliorated brain damage in animal studies (8). Initial enthusiasm, however, was dampened by the fact that in adult rats, resuscitative hypothermia of short duration $\left(30^{\circ} \mathrm{C}\right.$ for $\left.3 \mathrm{~h}\right)$ merely delayed the ultimate loss of hippocampal neurons 2 mo later (9). On the other hand, deep hypothermia in adult dogs showed an unfavorable outcome compared with normothermic controls, due to systemic side effects of deep hypothermia (10). Finally, prolongation $(5-48 \mathrm{~h})$ of mild to moderate resuscitative hypothermia in subsequent studies resulted in larger therapeutic windows (initiation of cooling delayed up to $12 \mathrm{~h}$ after insult) and persistent neuroprotection $(2-6 \mathrm{mo})$ in adult gerbils and rats $(11,12)$.

In the immature brain, studies of successful postischemic hypothermia either used no interventional delay $(13,14)$, or long-term benefits of delayed hypothermia were not documented $(15,16)$ - both factors being of major clinical interest in the treatment of perinatal asphyxia. Because differences in interventional delay or in outcome measures between animal model and clinical setting may partly explain the notorious failure of neuroprotective treatments in humans despite impressive success in animal models (17-19), we felt compelled to adjust our previously used neonatal animal model to the clinical situation before investigating in clinical trials (20). In addition, the results obtained in adult animals cannot directly be transposed onto neonatal animals because the latter are more resistant to HI and show a faster evolution of the injury thereafter (3).

The aim of this study was to test whether delayed resuscitative total body cooling of $26 \mathrm{~h}$ duration after severe $\mathrm{HI}$ in neonatal rats would a) reduce brain damage and b) minimize long-lasting functional deficits throughout brain maturation and into adulthood.

\section{METHODS}

The animal studies were approved by the Animal Care and Experimentation Committees of the States of Zurich and Bern, Switzerland. Guidelines for animal care, research and ethics published by the Swiss National Academy of Medical Sciences were strictly adhered to.

Model of cerebral HI. Our animal preparation was derived from that developed by Rice (21), and has been extensively studied by our group (20, 22-24). In brief, a total of 347 -d-old Sprague-Dawley rats with body weight of $17 \pm 0.6 \mathrm{~g}$ (mean \pm SEM) underwent right common carotid artery ligation under anesthesia $(0.5 \%-1 \%$ halothane in a $70 \%: 30 \%$ mixture of $\mathrm{N}_{2} \mathrm{O}: \mathrm{O}_{2}$ ). After ligation, the animals were returned to their dams and placed in a specially designed cage, which maintained a constant rectal temperature by servoregulating the water temperature in the cage walls. Rectal temperature was found to be representative of the brain temperature in the 7 -d-old rat $(25,26)$. One hour after surgery, neonatal rats were placed in a box where hypoxia with $8 \%$ oxygen (and $0.5 \%$ halothane) was maintained for $75 \mathrm{~min}$ at $37^{\circ} \mathrm{C}$ rectal temperature. Another $30 \mathrm{~min}$ of hypoxia were added while performing the first MRI. After a total of 105 min of hypoxia, all animals were returned to their dams in the temperature-controlled cage. Two hours after insult, one group of animals (group IN; $n=$ 17) was maintained at $37^{\circ} \mathrm{C}$ rectally for another $26 \mathrm{~h}$, whereas a second group of animals (group IH; $n=17$ ) was cooled to $30^{\circ} \mathrm{C}$ rectally and kept at this temperature for $26 \mathrm{~h}$. The temperature was confirmed by repetitive measurements with a rectal probe. Nesting rectal temperature of 7-d-old rats may vary due to their reduced homeostatic thermoregulatory response. We chose "normothermic" temperature to be $37^{\circ} \mathrm{C}$ rectally, to unify postischemic temperature in group IN like in other neonatal animal studies of postischemic hypothermia; and corresponding to the actual clinical practice in human newborns. After $26 \mathrm{~h}$ of normothermia or hypothermia, respectively, all animals were brought back to normal cages for the rest of the experiment at ambient room temperature of $25^{\circ} \mathrm{C}$, $50 \%$ humidity and a $12-\mathrm{h}$ day/night cycle.

In previous experiments, we noted that 7-d-old pups with 90 min of hypoxia after carotid ligation would die $5 \mathrm{~d}$ later due to poor suckling and persistent weight loss (20). To obtain longterm survival despite very severe cerebral insult, all hypoxicischemic pups were intermittently gavage fed for partial nutritional support, as suggested by the principle of permissive underfeedings in acute illness (27). The nutritional support consisted of $0.5 \mathrm{~mL}$ of formula feedings (commercially available condensed milk) started $6 \mathrm{~h}$ after hypoxia and continued every $6 \mathrm{~h}$ for $2 \mathrm{~d}$, and then slowly weaned over $3 \mathrm{~d}$ depending upon weight gain. The total amount of formula given was similar for both groups IN and IH.

Group IN as well as group IH were supplemented by control animals (groups $\mathrm{CN}$ and $\mathrm{CH}, n=14$ each) in such a way that each dam raised 2-3 hypoxic-ischemic pups together with 3-4 controls. We refrained from evaluating an additional group of animals with carotid artery ligation only, inasmuch as it has been demonstrated that ligation neither produced brain damage (22) nor functional impairments $(13,28,29)$. A total of 62 rats were used in the experiment. In group IN (IH, respectively), 5 (6) rats died during MRI and 2 (1) rats during gavage feedings. The high mortality rate during initial MRI was the result of the very severe cerebral insult combined with anesthesia necessary for good imaging quality.

Magnetic resonance imaging. Repetitive $\mathrm{T}_{2} \mathrm{WI}$ and $\mathrm{DWI}$ was used to document the dynamics of brain edema and infarction, analogous to previous studies of combined MRI and histopathology (20, 22-24). MRI was performed in all animals of groups IN and IH; at the end of HI, and at 2, 12, and $24 \mathrm{~h}$, as well as at 10 and $42 \mathrm{~d}$ of recovery. During the MR procedure, the animals were kept in a thermoregulated animal holder under anesthesia, and rectal temperature was controlled. $\mathrm{T}_{2}$ WI were acquired with a multislice rapid acquisition with relaxation enhancement (RARE) technique (30), with time to repeat $(\mathrm{TR})=4 \mathrm{~s}$, RARE factor $=16$, and interecho interval $=22 \mathrm{~ms}$ resulting in an effective echo time $\mathrm{TE}_{\text {eff }}=252 \mathrm{~ms}$. The matrix size was $256 \times 128$ (pixel dimensions $156 \times 312$ $\mu \mathrm{m})$ and the field of view (FOV) $=4 \mathrm{~cm}^{2}$. DWI was performed with stimulated echoes using the following acquisition parameters: TE $=18 \mathrm{~ms}, \mathrm{TR}=2 \mathrm{~s}$, diffusion weighting factor $\mathrm{b}=$ $1290 \mathrm{~s} / \mathrm{mm}^{2}$, matrix size $=128 \times 64$, FOV $=4 \mathrm{~cm}^{2}$ (31). The 
slice packages for the $\mathrm{T}_{2} \mathrm{WI}$ and DWI consisted of eight $1.5-\mathrm{mm}$-thick slices in the axial plane interleaved by a $0.3-\mathrm{mm}$ gap, covering the entire brain. All measurements were performed on a 2 TESLA (T) whole-body MR system (BrukerMedical, Faellanden, Switzerland) equipped with an actively shielded gradient insert with $33-\mathrm{cm}$ bore, maximal gradient strength of $30 \mathrm{mT} / \mathrm{m}$ and $150 \mu$ s rise time. Fractional extent of brain edema or infarction was calculated from MR images on each slice and summed to yield the entire volume of the lesion. In DWI, the hyperintense regions were interpreted as cytotoxic edema and hypointense regions as vasogenic edema, whereas in $\mathrm{T}_{2} \mathrm{WI}$ vasogenic edema and tissue liquefaction appeared hyperintense. The extent of the lesion size was determined by measuring the hyperintense area in DWI at $0,2,12$, and $24 \mathrm{~h}$ after injury, and in $\mathrm{T}_{2} \mathrm{WI}$ at 10 and $42 \mathrm{~d}$ after insult. To correlate functional performance with morphologic outcome at $42 \mathrm{~d}, \mathrm{~T}_{2} \mathrm{WI}$, residual volumes of ipsilateral and contralateral cortex, hippocampus, and striatum were calculated with the same procedure as described for the fractional extent of total brain lesion. The brain regions were identified from MRI by comparison with standard histologic slices from the atlas of Paxinos.

Behavioral testing. Weekly behavioral tests were performed by one person in the same quiet research facility during the morning hours. Because MRI and histopathology showed predominantly damages to the cortex, the striatum, and the hippocampus, three corresponding behavioral testing procedures were chosen: sensory motor function testing for cortical integrity, circling behavior for striatal function, and spatial memory for hippocampal testing. Spatial memory was assessed by a modified MWM test (28) performed $5 \mathrm{wk}$ after the insult. A square tub (length $65 \mathrm{~cm}$, height $50 \mathrm{~cm}$ ) was filled to a depth of $20 \mathrm{~cm}$ with $20^{\circ} \mathrm{C}$ water, and milk was added to decrease visual cues. A platform was placed $1.5 \mathrm{~cm}$ below the water surface and kept at the same location. One trial consisted of placing the rat by hand into the water facing an extramaze cue. If the rat successfully localized the submerged platform by climbing on it, the time was noted. The rat was permitted to recover at the warm extramaze cue for 10-20 s before the next trial was started. If the animal was unsuccessful in locating the platform, the trial was terminated after $120 \mathrm{~s}$ of swimming. The test ended as soon as the cumulative swimming time surpassed $360 \mathrm{~s}$, or when the rat had 10 trials. The escape latency, i.e. the average time per trial and animal, was then calculated.

Sensory motor functions were evaluated by using a treadmill test (Rota-Rod treadmill with diameter of $7 \mathrm{~cm}$, and $50 \mathrm{~cm}$ above ground) $4 \mathrm{wk}$ after the insult (32). For adaptation, the animals were placed first on the silent treadmill for $30 \mathrm{~s}$, and then the rotating treadmill was set in motion at a constant speed of 18 turns per minute. If the animal fell off the treadmill, the timer stopped and the animal was placed back on the treadmill for another trial. Each animal was given five trials, with a maximum time of $300 \mathrm{~s}$ per trial.

Circling behavior was assessed $6 \mathrm{wk}$ after the cerebral insult by systemic application of apomorphine. As dopamine agonist, apomorphine induces potent circling behavior in animals with unilateral striatal lesions (32). Immediately after intraperitoneal injection of apomorphine hydrochloride in saline $(1 \mathrm{mg} / \mathrm{kg}$ i.p.; Sigma Chemical St. Louis, MO, U.S.A.), the animals were placed in automated rotometer cylinders (Columbus Instruments, Columbus, OH, U.S.A.) and monitored for $60 \mathrm{~min}$. Complete turns were quantified by a computer (Videomax, Columbus Instruments) (33). The first 10 min were omitted from analysis. During the residual $50 \mathrm{~min}$, all clockwise rotations were subtracted from counterclockwise rotations and the final sum of asymmetrical rotations was calculated. The absolute value of the final sum was taken for group analysis to catch both ipsi- and contralateral pathologic circling behavior.

Statistical analysis. Statistical analysis was performed with StatXact 4.0.1 (Cytel Software, Cambridge, MA, U.S.A.). The evolution of the lesion extensions was analyzed after rank transformation using two-way-ANOVA for repeated measurements, and pair-wise comparisons in the post hoc analysis were performed with the Student-Newman-Keuls method. For comparisons of the behavioral tests and of the residual brain volumes, two-sided exact tests were performed (WilcoxonMann-Whitney or Wilcoxon-Gehan test). Correlation of regional brain volumes with corresponding behavioral performance was analyzed with Spearman's test. All values are mean \pm SEM.

\section{RESULTS}

The hypothermic animals tolerated the cooling without apnea or shivering. During the hypothermic experiment, group IH had significantly lower rectal temperatures than group $\mathrm{CH}$ $\left(29.8 \pm 0.2^{\circ} \mathrm{C}\right.$ versus $\left.31.3 \pm 0.1^{\circ} \mathrm{C}, p<0.001\right)$. This temperature difference was probably due to hypoxic suppression of the homeostatic metabolic response to hypothermia (34). During normothermia, group IN had comparable rectal temperatures to group $\mathrm{CN}$ (both with $36.7 \pm 0.1{ }^{\circ} \mathrm{C}$ ).

Magnetic resonance imaging. The temporal evolution of the brain lesion, assessed by MRI $\left(\mathrm{T}_{2} \mathrm{WI}\right.$ and $\left.\mathrm{DWI}\right)$ was described previously in detail $(20,24)$. In brief, at the end of the hypoxic period, an extensive cytotoxic edema covered the entire cortex, hippocampus, basal ganglia, thalamus ipsilateral to the ligation, which was similar in size in both groups IN and $\mathrm{IH}(47 \pm 3 \%$ and $45 \pm 4 \%$ of total brain volume in groups IN and IH, respectively) (Figs. 1 and 2). Occasionally, parts of the contralateral cortex and hippocampus were affected. After $2 \mathrm{~h}$ of recovery, the cytotoxic edema resolved almost completely, leaving only the central core lesion in the cortex (second image of Fig. 1). Core size was similar for the two groups (10.6 \pm $2.6 \%$ and $6.4 \pm 1.7 \%$ of total brain volume in groups IN and $\mathrm{IH}$, respectively) (Figs. 1 and 2). During the next hours, the edema expanded reaching a second maximal extent at $24 \mathrm{~h}$ of recovery. Ten days after the insult, high signal intensity on $\mathrm{T}_{2} \mathrm{WI}$ indicated tissue resorption; and $42 \mathrm{~d}$ after the insult, the infarction resulted in complete tissue loss in the ipsilateral parietal and cingulate cortex, and parts of hippocampus, basal ganglia, and thalamus. Delayed hypothermia led to a reduction of the lesion size (expressed as percentage of total brain volume) throughout the whole observation period (36 $\pm 4 \%$, $43 \pm 3 \%, 27 \pm 3 \%, 39 \pm 2 \%$ in group IN versus $22 \pm 3 \%, 35$ $\pm 2 \%, 20 \pm 2 \%, 30 \pm 2 \%$ in group $\mathrm{IH} ; 12 \mathrm{~h}, 24 \mathrm{~h}, 10 \mathrm{~d}$, and $42 \mathrm{~d}$ after insult) (Figs. 1 and 2). Significant reductions were 


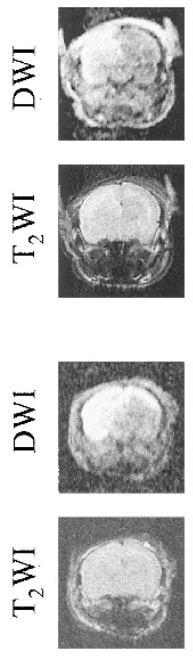

$0 \mathrm{~h}$
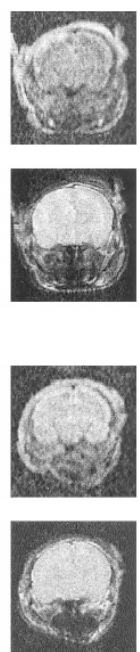

$2 \mathrm{~h}$
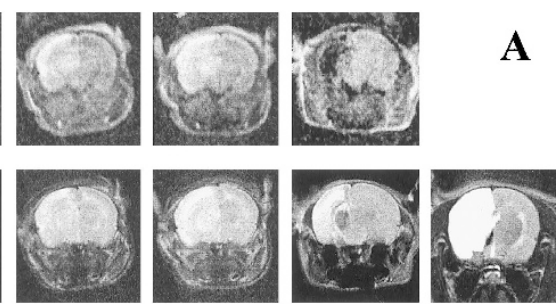

A

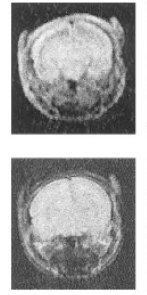

$12 \mathrm{~h}$

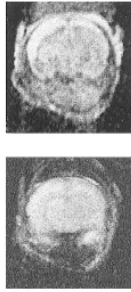

$24 \mathrm{~h}$

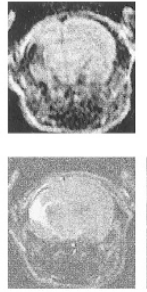

$10 \mathrm{~d}$

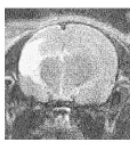

$42 \mathrm{~d}$
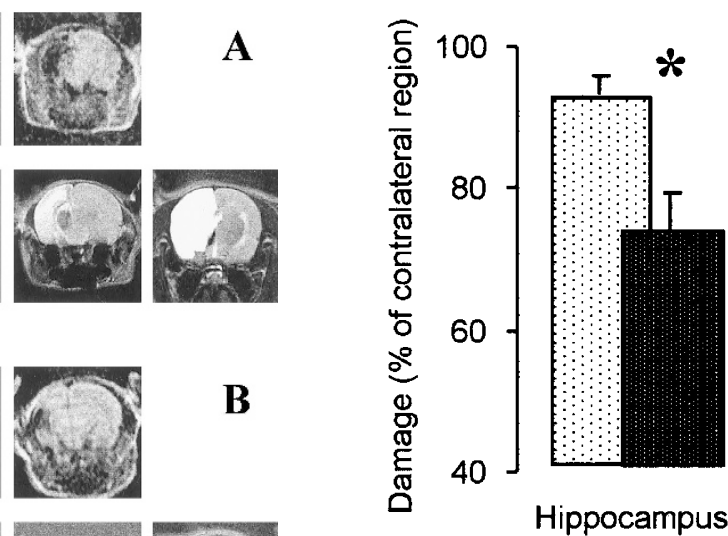

Figure 1. Evolution of brain edema/infarction with magnetic resonance diffusion (DWI, first row) and $\mathrm{T}_{2}$-weighted imaging ( $\mathrm{T}_{2} \mathrm{WI}$, second row) in a representative 7 -d-old rat pup after right common carotid artery ligation and $8 \% \mathrm{O}_{2}$ exposure for $105 \mathrm{~min}$. Images taken at the end of hypoxia-ischemia ( 0 h); 2, 12, and $24 \mathrm{~h}$, and 10 and $42 \mathrm{~d}$ after insult. (A) Animal recovered in normothermic conditions for $28 \mathrm{~h}$. $(B)$ Two hours after normothermic recovery, animal was cooled to $30^{\circ} \mathrm{C}$ rectal temperature for $26 \mathrm{~h}$.

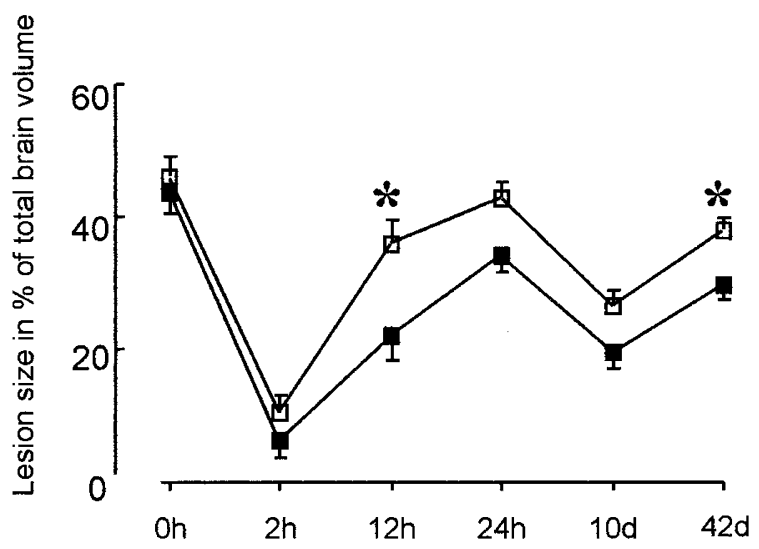

Figure 2. Evolution of edema and infarction size after experimental cerebral $\mathrm{HI}$ in 7-d-old rats, determined by MR imaging. Open square = normothermia; filled square $=$ hypothermia delayed $2 \mathrm{~h}$. The extent of the initial cytotoxic edema at $0 \mathrm{~h}$ and $2 \mathrm{~h}$ after HI was similar in both animal groups. However, delayed resuscitative hypothermia $\left(30^{\circ} \mathrm{C}\right.$ rectal temperature for $\left.26 \mathrm{~h}\right)$ significantly reduced edema size at $12 \mathrm{~h}$ as well as infarction size at $42 \mathrm{~d}$ after insult. $* p<0.05$ compared with normothermia. Values are mean \pm SEM.

found $12 \mathrm{~h}$ and $42 \mathrm{~d}$ after severe insult of the neonatal brain, corresponding to a final adult brain tissue savings of $23 \%$ (30\% lesion size in group IH versus $39 \%$ in group IN). Differences of rescued brain tissue in respect to size and region could be observed (Fig. 3). Residual volumes $\left(\mathrm{mm}^{3}\right)$ of affected ipsilateral and intact contralateral hippocampus (group IN $8 \pm 3$ and $103 \pm 19$; group IH $28 \pm 7$ and $107 \pm 7$ ), striatum (group IN $47 \pm 9$ and $151 \pm 12$; group IH $61 \pm 8$ and $157 \pm 7$ ), and cortex (group IN $96 \pm 23$ and $603 \pm 17$; group IH $150 \pm 31$ and $591 \pm 23$ ) were calculated from the $\mathrm{d} 42 \mathrm{MRI}$. The largest rescue was found in the hippocampus ( $21 \%$ tissue savings, $p=$ $0.031)$. The smaller rescues in cortex $(11 \%, p=0.160)$ and in striatum $(13 \%, p=0.143)$ did not reach statistical significance.
Figure 3. Regional differences in delayed hypothermic rescue $42 \mathrm{~d}$ after experimental cerebral $\mathrm{HI}$ in neonatal rats. Light shaded bars = normothermia; dark shaded bars $=2 \mathrm{~h}$ delayed hypothermia. Twenty-six hours of $30^{\circ} \mathrm{C}$ hypothermia reduced significantly brain damage in the hippocampus, whereas reduction in the striatum or cortex did not reach significance. ${ }^{*} p<0.01$ compared with normothermia.

Table 1. Effects of delayed hypothermia on behavioral performance

\begin{tabular}{lccc}
\hline & $\begin{array}{c}\text { Spacial memory } \\
(\mathrm{s})\end{array}$ & $\begin{array}{c}\text { Circling behavior } \\
\text { (turns) }\end{array}$ & $\begin{array}{c}\text { Sensory motor } \\
\text { functions (s) }\end{array}$ \\
\hline Groups (n) & & & \\
Group IN (10) & $101 \pm 4$ & $51 \pm 13$ & $256 \pm 107$ \\
Group IH (10) & $61 \pm 12$ & $37 \pm 19$ & $328 \pm 99$ \\
Group CH (14) & $33 \pm 7$ & $8 \pm 2$ & $539 \pm 118$ \\
Group CN (14) & $35 \pm 9$ & $6 \pm 1$ & $599 \pm 84$ \\
$p$ Values & & & \\
IN vs. IH & 0.026 & 0.31 & 0.62 \\
IN vs. CN & 0.000 & 0.001 & 0.001 \\
IH vs. CH & 0.025 & 0.02 & 0.08 \\
CN vs. CH & 0.94 & 0.38 & 0.36 \\
\hline
\end{tabular}

Morris Water Maze test (escape latency in seconds) was used to assess spatial memory; systemic apomorphine (sum of asymmetrical rotations) for circling behavior; and treadmill test (treadmill performance in seconds) for sensory motor functions. Values are mean \pm SEM.

Behavioral tests. The results of behavioral tests are summarized in Table 1. Control animals did not demonstrate any behavioral differences between group $\mathrm{CN}$ and group $\mathrm{CH}$. Group IN showed inferior performance in all behavioral tests when compared with group $\mathrm{CN}$. Delayed hypothermia significantly shortened escape latency of hypoxic-ischemic animals (group IH versus group IN); however, latency remained significantly longer when compared with healthy animals (group $\mathrm{IH}$ versus group $\mathrm{CH}$ ). Although not quantified by videocamera recording and computer analysis, group IN did not demonstrate any difficulties with swimming or with platform climbing. On the contrary, group IN showed speedy and stereotyped swimming, whereas groups $\mathrm{CN}$ and $\mathrm{CH}$ revealed a more quiet and varied zigzag swimming behavior. Total body cooling also improved sensory motor dysfunctions and circling abnormalities (group IH versus group IN); however, this difference did not reach statistical significance.

Comparing brain morphology with function, significant correlations could be found between MWM test performance and hippocampal residual volume, between treadmill test performance and cortical residual volume, and between apomorphine test performance and striatal residual volume (Fig. 4). 

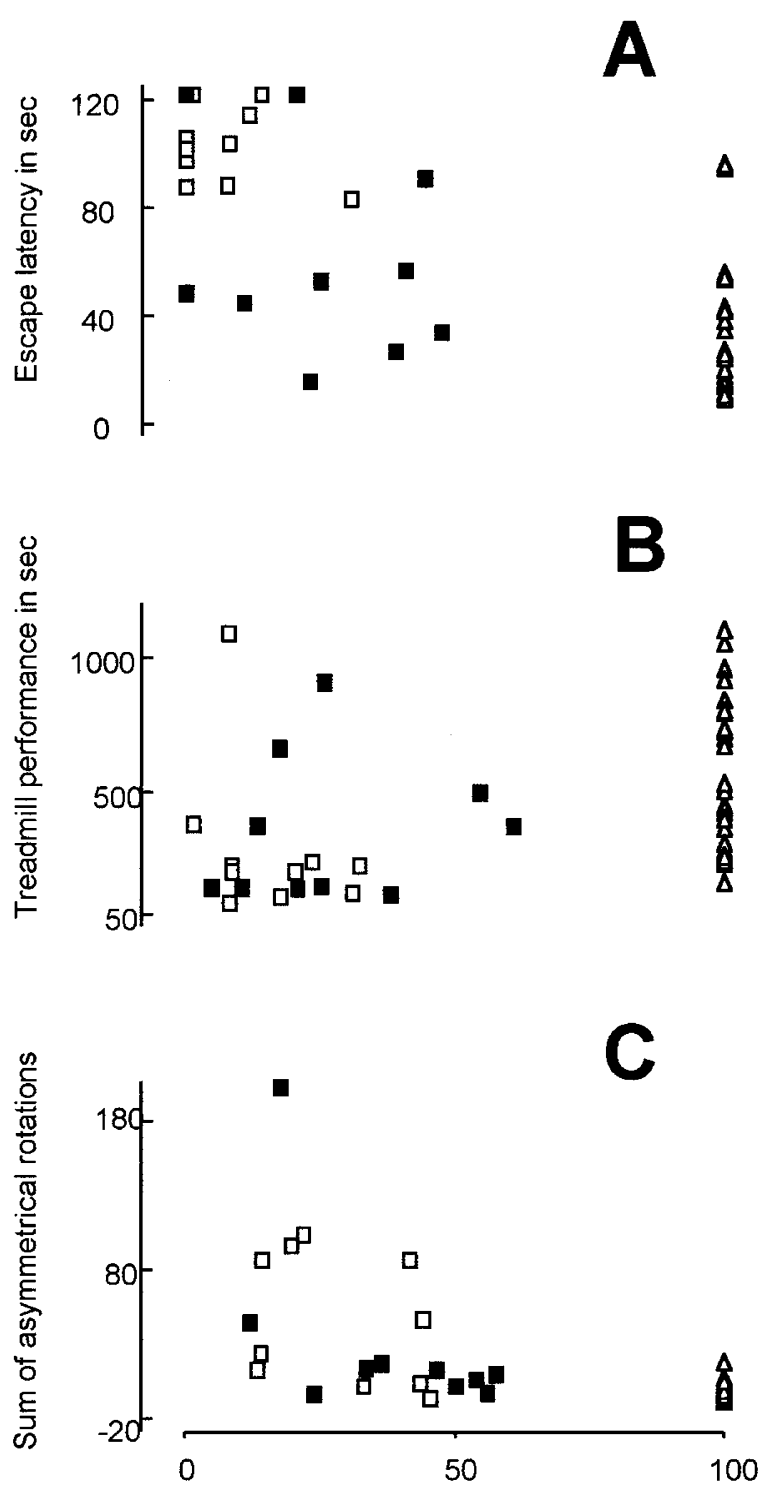

Regional brain volume (\% of contralateral region)

Figure 4. Correlation of behavioral performance with corresponding ipsilateral regional brain volume after cerebral HI. Open squares = normothermia; filled squares $=2 \mathrm{~h}$ delayed hypothermia; open triangles $=$ controls. In controls, regional brain volume was estimated as $100 \%$ of contralateral side. (A) Spatial memory vs. hippocampal volume; $r=-0.657, p<0.001$. (B) Sensory motor functions $v$ s. residual cortical volume; $r=0.471, p<0.001$. (C) Circling behavior vs. striatal volume; $r=-0.644, p<0.001$.

\section{DISCUSSION}

The hypothesis of this study was that prolonged resuscitative hypothermia $\left(30^{\circ} \mathrm{C}\right.$ for $\left.26 \mathrm{~h}\right)$ would not only limit morphologic damage, but would improve long-lasting functional deficits seen after severe hypoxic-ischemic insult in the neonatal brain, even if initiation of hypothermia were delayed by $2 \mathrm{~h}$. In fact, brain infarction was reduced by $23 \%$ at 6 wk after the insult and the largest tissue rescue was found in the hippocampus. In addition, cooling significantly diminished spatial memory deficits, known to depend mainly upon hippocampal damage. These data demonstrate that despite severe cerebral HI and delay of postischemic hypothermic intervention, resuscitative total body cooling for $26 \mathrm{~h}$ significantly improved long-term neurobehavioral achievements when tested during the subsequent phase of brain maturation and even into adulthood.

So far, therapeutic interventions of hypothermia after severe hypoxic-ischemic injury of the immature animal brain have remained controversial. When applying short duration of mild cooling immediately after the cerebral insult, either no effect $(25,35,36)$, or only short-term protection was found (26, 37-41), which, considering the very delayed cell death observed after hypothermia in adult animals (12), may be transient. Long-term brain tissue protection was obtained when immediate, postischemic hypothermia $\left(32^{\circ} \mathrm{C}\right)$ was prolonged for $6 \mathrm{~h}$ after neonatal HI; however sensory motor dysfunctions did not diminish (13). And when delaying onset of cooling (6 h) after the insult, the morphologic improvements were lost 3 wk later, despite prolonged use of mild hypothermia for $66 \mathrm{~h}$ (14). Further studies with delayed onset $(5 \mathrm{~h})$ and selective head cooling $\left(32^{\circ} \mathrm{C}\right.$ for $\left.72 \mathrm{~h}\right)$ in fetal lambs demonstrated short-term neuronal salvage $5 \mathrm{~d}$ after insult, but did not examine protracted neuroprotective effects $(15,16)$.

The current study was the first to achieve long-lasting behavioral improvement when using delayed and prolonged resuscitative total body hypothermia after severe cerebral HI to the neonatal brain. Our findings are in agreement with the results of the only adult study documenting behavioral benefits up to 6 mo after delayed hypothermia (11). Taken together, these studies showed that effective and possibly permanent functional advantages could be obtained if mild to moderate hypothermia $\left(30-32^{\circ} \mathrm{C}\right)$ was induced within $1-2 \mathrm{~h}$ after hypoxic-ischemic injury and if it was applied over a prolonged time period of at least $24 \mathrm{~h}$. When extrapolating from morphologic studies in adult animals, it is likely that a larger degree or further prolongation of cooling might improve behavioral rescue and/or widen the therapeutic window (12).

On the other hand, prolonged cooling might increase the risk of hypothermic side effects, reducing neuroprotective benefits (10). Our study was not designed to look at various hypothermic side effects. If present, however, these side effects did not influence measured outcome variables, inasmuch as group $\mathrm{CH}$ showed identical behavioral performance when compared with group CN (Table 1). Our study represents the only published safety study in regard to hypothermic impact on behavior, because other studies of long-term functional outcome after postischemic hypothermia did not compare hypothermic with normothermic controls $(11,13)$. Nevertheless, given the multitude of factors that affect neuroprotection, it is evident that the optimal hypothermic parameters for best outcome at minimal side effects will have to be worked out in the clinic.

Our observation of significantly impaired functions in animals after neonatal cerebral hypoxic-ischemic insult were consistent with the findings of previous studies reporting impairment of spatial memory (28), circling behavior $(32,42)$, or sensory motor functions $(29,32)$ in the same animal model. We purposely chose behavioral tests adapted to the young age of the animal, which have previously been shown to unravel behavioral deficits at specific time points after cerebral $\mathrm{HI}$ in the 7-d-old rat animal model $(28,32)$. These criteria were also fulfilled by the modified MWM test used here, which con- 
trasted with more sophisticated setups used in older animals allowing for additional precision measure by the spatial probe task, and allowing for sensory motor deficits control by visible platform task (43). In fact, by using a whole battery of functional tests in the present study, hypoxic-ischemic animals were found to have significant sensory motor deficits and circling abnormalities, both possibly contributing to the prolonged escape latency found in the modified MWM test. However, because hypothermia significantly shortened latency without improving treadmill performance or circling behavior, and because there was a significant correlation between latency and residual hippocampal volume, we conclude that improvement in spatial memory is most likely the reason for the observed hypothermic rescue of escape latency.

Our observation of weak but significant correlations between individual behavioral performance and residual brain volume (Fig. 4) confirmed other studies reporting correlations between magnitude of behavioral impairment and respective tissue damage for hippocampus (43), striatum (33), and cortex (29). In contrast, other studies have shown a discrepancy between histologic damage and functional impairment, and several factors may potentially obfuscate this relationship $(11,44)$. The risk of nonlinear relationship between morphology and function, as well as the risk of loss of neuroprotective effectiveness by interventional delay, may demand preclinical evaluation of the therapeutic window and of the long-term behavioral benefits of any agent with neuroprotective features. Omission of such experimental testing may contribute to the high failure rate actually seen in clinical drug trials $(3,19)$. As a matter of fact, the authors found in the literature only three other successful neuroprotective measures after cerebral ischemia in adult animals, which were able to produce long-term functional improvements ( $>4 \mathrm{wk})$ after delayed onset of intervention $(>1$ h) $(11,45,46)$.

Interesting to note are the regional differences of hypothermic rescue found in the current study. This may directly relate to regional graduation of injury severity in the animal model. Because the brain protective effect of cooling depends upon severity of insult, a less injured hippocampus may have profited more than cortex or striatum. In the same animal model, Bona et al. (13) also reported a hippocampal preference in hypothermic recovery, whereas a model of global ischemia lacked any regional preference $(15,16)$.

New insights into the effects of postischemic hypothermia in the immature and adult brain support the use of delayed neuroprotective resuscitation. Postischemic cooling acts on several early and late mechanisms such as preservation of mitochondrial respiration rates (47), amelioration of delayed, secondary energy failure and lactate accumulation $(20,39)$, blunting of excitatory amino acids and nitric oxide release (48), improved recovery of somatosensory evoked potential amplitude and of normal coupling of cerebral metabolic rate (49), and specific inhibition of apoptosis (37). In summary, postischemic hypothermia is likely to exert synergistic neuroprotective effects through preservation of energy metabolism and reduction of toxic metabolites.

In conclusion, hypothermia is presently the most promising resuscitative intervention with significant neuroprotection. It even allows postischemic interventional delay, as would be the case in the clinical situation, without loss of long-term effectiveness. The preclinical evaluation of hypothermic rescue after acute cerebral $\mathrm{HI}$ in the immature brain appears now to be in an advanced stage and strongly supports collaborative evaluation of total body cooling in human newborns suffering from perinatal asphyxia.

Acknowledgments. The authors thank Dr. H.R. Widmer, Division of Neurosurgical Research, and Dr. R, Amman, Medical Statistics of the Department of Pediatrics, University of Berne, for critical review of the study.

\section{REFERENCES}

1. Committee on Fetus and Newborn, American Academy of Pediatrics, and Committee on Obstetric Practice, American College of Obstetricians and Gynecologists 1996 Use and abuse of the Apgar score. Pediatrics 98:141-142

2. Roland EH, Poskitt K, Rodriguez E, Lupton BA, Hill A 1998 Perinatal hypoxicischemic thalamic injury: clinical features and neuroimaging. Ann Neurol 44:161166

3. Vannucci RC, Perlman JM 1997 Interventions for perinatal hypoxic-ischemic encephalopathy. Pediatrics 100:1004-1014

4. Dunn JM, Miller Jr JA 1969 Hypothermia combined with positive pressure ventilation in resuscitation of the asphyxiated neonate. Clinical observations in 28 infants. Am J Obstet Gynecol 104:58-67

5. Cordey R, Chiolero R, Miller Jr JA 1973 Resuscitation of neonates by hypothermia: report on 20 cases with acid-base determination on 10 cases and the long-term development of 33 cases. Resuscitation 2:169-181

6. Williams GR, Spencer JA 1958 The clinical use of hypothermia following cardiac arrest. Ann Surg 148:462-466

7. Silverman WA, Fertig JW, Berger AP 1958 The influence of the thermal environment upon the survival of newly born premature infants. Pediatrics 22:876-885

8. Busto R, Dietrich WD, Globus MY, Ginsberg MD 1989 Postischemic moderate hypothermia inhibits CA1 hippocampal ischemic neuronal injury. Neurosci Lett 101:299-304

9. Dietrich WD, Busto R, Alonso O, Globus MY, Ginsberg MD 1993 Intraischemic but not postischemic brain hypothermia protects chronically following global forebrain ischemia in rats. J Cereb Blood Flow Metab 13:541-549

10. Weinrauch V, Safar P, Tisherman S, Kuboyama K, Radovsky A 1992 Beneficial effect of mild hypothermia and detrimental effect of deep hypothermia after cardiac arrest in dogs. Stroke 23:1454-1462

11. Colbourne F, Corbett D 1995 Delayed postischemic hypothermia: a six month survival study using behavioral and histological assessments of neuroprotection. J Neurosci 15:7250-7260

12. Colbourne F, Sutherland GR, Auer RN 1999 Electron microscopic evidence against apoptosis as the mechanism of neuronal death in global ischemia. $\mathrm{J}$ Neurosci 19:4200-4210

13. Bona E, Hagberg H, Loberg EM, Banasiak K, Thoresen M 1998 Protective effects of moderate hypothermia after neonatal hypoxia-ischemia: short- and long-term outcome. Pediatr Res 43:738-745

14. Sirimanne ES, Blumberg RM, Bossano D, Gunning M, Edwards AD, Gluckman PD, Williams CE 1996 The effect of prolonged modification of cerebral temperature on outcome after hypoxic-ischemic brain injury in the infant rat. Pediatr Res 39:591-597

15. Gunn AJ, Gunn TR, de Haan HH, Williams CE, Gluckman PD 1997 Dramatic neuronal rescue with prolonged selective head cooling after ischemia in fetal lambs. J Clin Invest 99:248-256

16. Gunn AJ, Gunn TR, Gunning MI, Williams CE, Gluckman PD 1998 Neuroprotection with prolonged head cooling started before postischemic seizures in fetal sheep. Pediatrics 102:1098-1106

17. Doppenberg EM, Bullock R 1997 Clinical neuro-protection trials in severe traumatic brain injury: lessons from previous studies. J Neurotrauma 14:71-80

18. Fisher M, Bogousslavsky J 1998 Further evolution toward effective therapy for acute ischemic stroke. JAMA 279:1298-1303

19. Muir KW, Grosset DG 1999 Neuroprotection for acute stroke: making clinical trials work. Stroke 30:180-182

20. Nedelcu J, Klein MA, Aguzzi A, Boesiger P, Martin E 2000 Resuscitative hypothermia protects the neonatal brain from hypoxic-ischemic injury. Brain Pathol 10:61-71

21. Rice III JE, Vannucci RC, Brierley JB 1981 The influence of immaturity on hypoxic-ischemic brain damage in the rat. Ann Neurol 9:131-141

22. Rumpel H, Buchli R, Gehrmann J, Aguzzi A, Illi O, Martin E 1995 Magnetic resonance imaging of brain edema in the neonatal rat: a comparison of short and long term hypoxia-ischemia. Pediatr Res 38:113-118

23. Rumpel H, Nedelcu J, Aguzzi A, Martin E 1997 Late glial swelling after acute cerebral hypoxia-ischemia in the neonatal rat: a combined magnetic resonance and histochemical study. Pediatr Res 42:54-59

24. Nedelcu J, Klein MA, Aguzzi A, Boesiger P, Martin E 1999 Biphasic edema after hypoxic-ischemic brain injury in neonatal rats reflects early neuronal and late glial damage. Pediatr Res 46:297-304 
25. Yager J, Towfighi J, Vannucci RC 1993 Influence of mild hypothermia on hypoxicischemic brain damage in the immature rat. Pediatr Res 34:525-529

26. Thoresen M, Bagenholm R, Lindberg EM, Apricena F, Kjellmer I 1996 Posthypoxic cooling of neonatal rats provides protection against brain injury. Arch Dis Child Fetal Neonatal Ed 74:F3-F9

27. Zaloga GP, Roberts P 1994 Permissive underfeeding. New Horiz 2:257-263

28. Young RS, Kolonich J, Woods CL, Yagel SK 1986 Behavioral performance of rats following neonatal hypoxia-ischemia. Stroke 17:1313-1316

29. Bona E, Johansson BB, Hagberg H 1997 Sensorimotor function and neuropathology five to six weeks after hypoxia-ischemia in seven-day-old rats. Pediatr Res 42:678683

30. Hennig J, Nauerth A, Friedburg H 1986 RARE imaging: a fast imaging method for clinical MR. Magn Reson Med 3:823-833

31. Merboldt KD, Hänicke W, Frahm J 1985 Self-diffusion NMR imaging using stimulated echoes. J Magn Reson 64:479-486

32. Jansen EM, Low WC 1996 Long-term effects of neonatal ischemic-hypoxic brain injury on sensorimotor and locomotor tasks in rats. Behav Brain Res 78:189-194

33. Meyer M, Widmer HR, Wagner B, Guzman R, Evtouchenko L, Seiler RW, Spenger C 1998 Comparison of mesencephalic free-floating tissue culture grafts and cell suspension grafts in the 6-hydroxydopamine- lesioned rat. Exp Brain Res 119:345355

34. Brück K 1998 Neonatal thermal regulation. In: Polin RA, Fox WF (eds) Fetal and Neonatal Physiology. WB Saunders, Philadelphia, pp 676-702

35. Yager JY, Asselin J 1996 Effect of mild hypothermia on cerebral energy metabolism during the evolution of hypoxic-ischemic brain damage in the immature rat. Stroke 27:919-925

36. Haaland K, Lindberg EM, Steen PA, Thoresen M 1997 Posthypoxic hypothermia in newborn piglets. Pediatr Res 41:505-512

37. Edwards AD, Yue X, Squier MV, Thoresen M, Cady EB, Penrice J, Cooper CE, Wyatt JS, Reynolds EO, Mehmet H 1995 Specific inhibition of apoptosis after cerebral hypoxia- ischaemia by moderate post-insult hypothermia. Biochem Biophys Res Commun 217:1193-1199

38. Thoresen M, Penrice J, Lorek A, Cady EB, Wylezinska M, Kirkbride V, Cooper CE, Brown GC, Edwards AD, Wyatt JS 1995 Mild hypothermia after severe transient hypoxia-ischemia ameliorates delayed cerebral energy failure in the newborn piglet. Pediatr Res 37:667-670

39. Amess PN, Penrice J, Cady EB, Lorek A, Wylezinska M, Cooper CE, DSouza P, Tyszczuk L, Thoresen M, Edwards AD, Wyatt JS, Reynolds EO 1997 Mild hypothermia after severe transient hypoxia-ischemia reduces the delayed rise in cerebral lactate in the newborn piglet. Pediatr Res 41:803-808

40. Laptook AR, Corbett RJ, Sterett R, Burns DK, Garcia D, Tollefsbol G 1997 Modest hypothermia provides partial neuroprotection when used for immediate resuscitation after brain ischemia. Pediatr Res 42:17-23

41. Trescher WH, Ishiwa S, Johnston MV 1997 Brief post-hypoxic-ischemic hypothermia markedly delays neonatal brain injury. Brain Dev 19:326-338

42. Silverstein F, Johnston MV 1984 Effects of hypoxia-ischemia on monoamine metabolism in the immature brain. Ann Neurol 15:342-347

43. Moser E, Moser MB, Andersen P 1993 Spatial learning impairment parallels the magnitude of dorsal hippocampal lesions, but is hardly present following ventral lesions. J Neurosci 13:3916-3925

44. Shuaib A, Murabit MA, Kanthan R, Howlett W, Wishart T 2041996 The neuroprotective effects of gamma-vinyl GABA in transient global ischemia: a morphological study with early and delayed evaluations. Neurosci Lett 204:1-4

45. Green EJ, Pazos AJ, Dietrich WD, McCabe PM, Schneiderman N, Lin B, Busto R, Globus MY, Ginsberg MD 1995 Combined postischemic hypothermia and delayed MK-801 treatment attenuates neurobehavioral deficits associated with transient global ischemia in rats. Brain Res 702:145-152

46. Kawamata T, Alexis NE, Dietrich WD, Finklestein SP 1996 Intracisternal basic fibroblast growth factor (bFGF) enhances behavioral recovery following focal cerebral infarction in the rat. J Cereb Blood Flow Metab 16:542-547

47. Canevari L, Console A, Tendi EA, Clark JB, Bates TE 1999 Effect of postischaemic hypothermia on the mitochondrial damage induced by ischaemia and reperfusion in the gerbil. Brain Res 817:241-245

48. Thoresen M, Satas S, Puka SM, Whitelaw A, Hallström A, Lindberg EM, Ungerstedt U, Steen PA, Hagberg H 1997 Post-hypoxic hypothermia reduces cerebrocortical release of NO and excitotoxins. Neuroreport 8:3359-3362

49. Baldwin WA, Kirsch JR, Hurn PD, Toung WS, Traystman RJ 1991 Hypothermic cerebral reperfusion and recovery from ischemia. Am J Physiol 261:H774-H781 